\title{
RECTAL DIVERTICULUM
}

\author{
Divertículo retal \\ Renato Borges FAGUNDES, Guilherme Lang MOTTA, Kalil FONTANA, Carla Bortolin FONSECA, Marcelo BINATO
}

From Gastroenterology Department of University Hospital of Santa Maria, Federal University of Santa Maria, Santa Maria, RS, Brazil.

\section{Correspondence: \\ Renato Borges Fagundes, e-mail: fagundesrb@gmail.com}

Financial source: none

Conflicts of interest: none

Received for publication: 23/07/2010

Accepted for publication: 30/02/2011

\section{INTRODUCTION}

$\mathrm{D}$ iverticular disease of the colon is a common condition in western and developed countries. Its prevalence increases with age, being present in more than 50\% of population aged over 80 in some series. Distal colon is the mainly stricken part, being the sigmoid colon affected in up to $70 \%$ of the patients ${ }^{6}$. Otherwise, the occurrence of rectal diverticula is extremely unusual. According to some series, this condition is found in only 0.07 to $0.08 \%$ of barium enema radiographics ${ }^{11,14}$ and in $2 \%$ to $2.4 \%$ of patients with diverticular disease of the colon ${ }^{12,14}$. Herein, four patients with rectal diverticula are reported and this condition is discussed based on a literature review.

\section{CASES REPORT}

Case 1) A 72 years old female complaining abdominal pain in the left-lower quadrant for two weeks. Pain usually was relieved after evacuations. She had medical history of obesity, arterial hypertension and had a prior hemorrhoidectomy. Flexible retossigmoidoscopy revealed multiple diverticula in sigmoid and a diverticulum in the right lateral wall of the rectum with an ostium of 3 $\mathrm{cm}$. Abdominal computed tomography and barium enema showed diverticular disease of transverse and sigmoid colon, as well as the rectal diverticulum.

Case 2) A 59 years old female suffering from pain in the left-lower quadrant of abdomen and diarrhea alternating to constipation for two years. Exception for obesity she had no significant medical history. Colonoscopy showed diverticular disease of descending and sigmoid colon associated with a diverticulum in the posterior wall of rectum. This diverticulum had an unusual small ostium $(0.7 \mathrm{~cm})$, a central depression and elevated margins.

Case 3) A 77 years old male presenting constipation and rectal pain for two weeks. Medical history revealed chagasic megacolon corrected by Duhamel's technique 14 years ago. He was a smoker and presented hypothyroidism, hypertension and diabetes mellitus. Colonoscopy showed rectal atony and dilatation, anatomical modifications from Duhamel's surgery and a rectal diverticulum with an ostium diameter of $2.5 \mathrm{~cm}$ in the posterior wall.

Case 4) A 56 years old male with recurrent episodes of severe pain in anal region, associated with constipation for six months. $\mathrm{He}$ also complained urinary alterations. He was a smoker and had no previous medical records. Barium enema and abdominal computed tomography showed diverticular disease of descending and sigmoid colon and a rectal diverticulum in the anterior wall of the rectum (Figure 1 ).

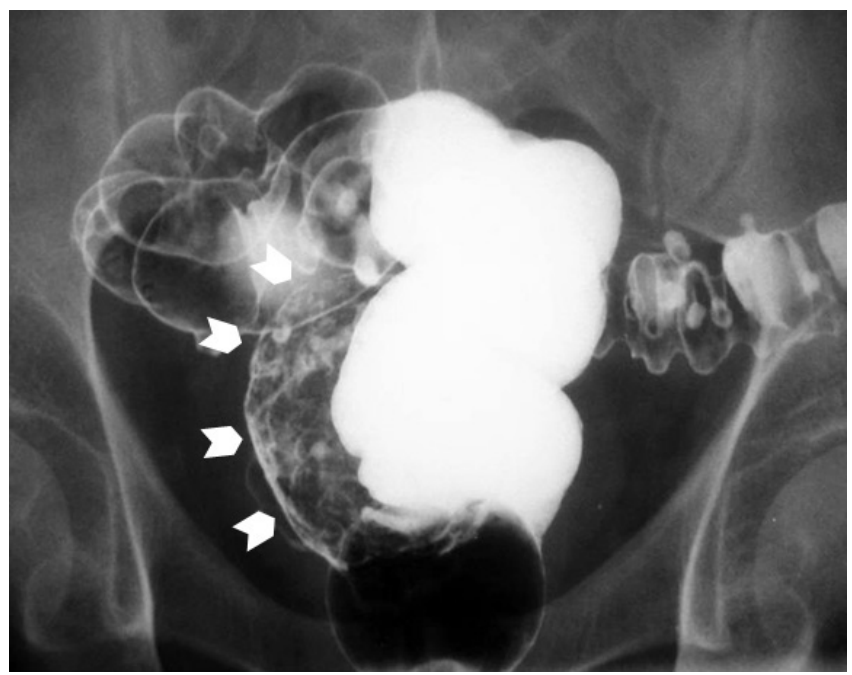

FIGURE 1 - Barium enema presenting diverticular disease of sigmoid colon and a large rectal diverticulum in the anterior wall of the rectum (arrows)

Flexible retossigmoidoscopy confirmed the large rectal diverticulum filled with fecaloma and an ostium diameter of $3 \mathrm{~cm}$. 
A pelvic ultrasound showed that the rectal diverticulum was $5.3 \mathrm{~cm}$ wide and it was compressing the bladder (Figure 2).

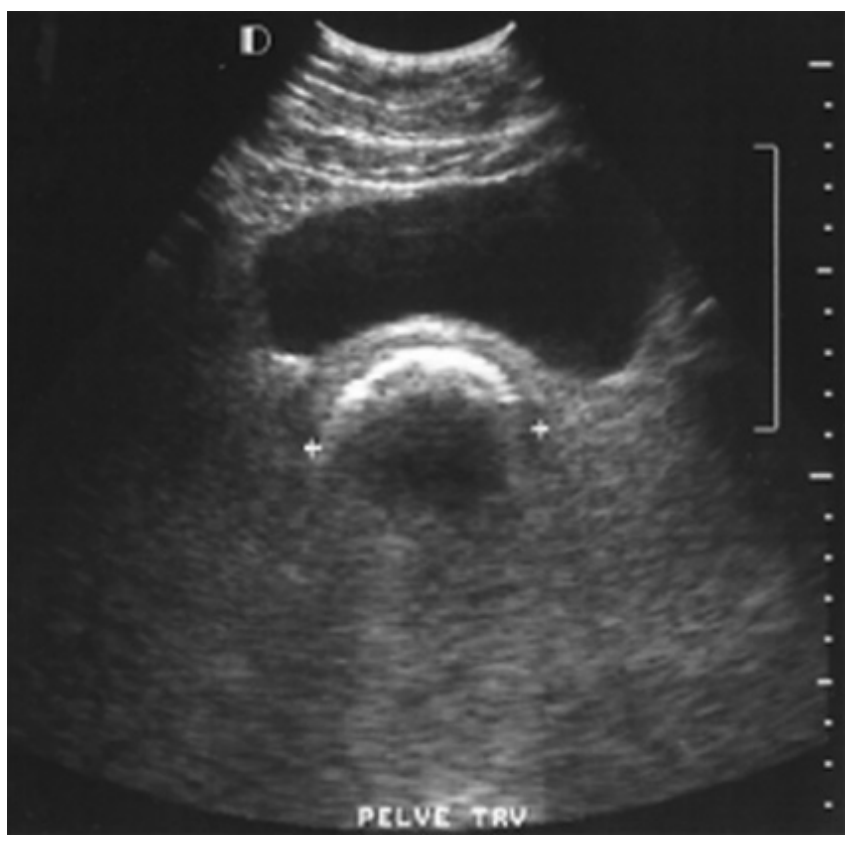

FIGURE 2 - Pelvic ultrasound showing the $5.3 \mathrm{~cm}$ diameter rectal diverticulum compressing the bladder

The patient underwent surgery and a single diverticulectomy was performed. Analysis of the resected diverticula revealed normal colonic tissue. One year and six months after diverticulectomy the patient was totally asymptomatic.

\section{DISCUSSION}

Rectal diverticula are rare. Most cases are asymptomatic and the finding is incidental. The true prevalence of this condition is hard to define. In a 4.854 barium enema, Walstad et al. ${ }^{14}$ found $0.08 \%$ of prevalence in all exams. Other series revealed a prevalence of $2 \%$ to $2.4 \%$ in patients with diverticular disease of the colon ${ }^{12,14}$. The most affected age group is from 55 to 85 years, and male patients are three times more affected ${ }^{1}$. The ten years prevalence of rectal diverticula in authors endoscopy unit is $0.15 \%$ of all colonoscopies, and $0.74 \%$ in patients with colonic diverticulosis.

Theories to explain the low prevalence of the rectum diverticula have been proposed. Anatomical disposition of the muscle layers on the rectum, especially in the anterior and posterior walls, promoting a major resistance to intraluminal variations could justify the lower prevalence of this condition compared to colonic diverticulosis ${ }^{15}$. Less intense rectal pressure and lesser peristaltic movements than sigmoid could be other reason to this low prevalence ${ }^{1,3}$. A report of rectal diverticulum in a newborn raises the possibility of this condition being congenital. This congenital theory is reinforced by the similarity with the diverticular form of the congenital duplication of the rectum ${ }^{7}$.

Rectal diverticula generally are unique, but cases of three diverticula in the same rectum have been reported ${ }^{1}$. In most cases the ostium diameter is $2 \mathrm{~cm}$ or more, while colonic diverticula generally present smaller ostium diameters ranging from 0.5 to $1.0 \mathrm{~cm}^{1,10}$. In contrast to colonic diverticulum, rectum diverticulum contains all wall layers; therefore it is considered a true diverticulum ${ }^{4}$. Usually rectal diverticulum is presented at endoscopic examination as a large ostium with communication to the rectum lumen in the lateral walls of the rectum ${ }^{9,11,12,14}$. They are often associated with diverticulosis and patient complaints are usually due to the colonic disease ${ }^{10}$. These four patients had diverticular disease of colon with the sigmoid affected in all cases.

Diverticula may manifest as diverticulitis, infections, ulceration, perforation, fistula, prolapse or perineal mass ${ }^{14}$. Diverticulitis occurs due to fecal impaction, trauma or other irritants. Infection leads to abscess formation if not treated properly. Perforation may occur, however it is less troublesome when compared with perforation of the colonic diverticula because they are located underneath the peritoneal reflection ${ }^{1,8}$. Both infection and perforation may result in fistula ${ }^{7}$. Large abnormal diverticula may prolapse through the anus or produce a perineal mass that enlarges during evacuation ${ }^{2,5}$. In this series, one patient presented rectal diverticulum with recurrent diverticulitis. The large fecaloma inside the diverticulum was the possible explanation for diverticulitis. This patient also had recurrent urinary changes caused by bladder compression as demonstrated by ultrasound.

Some factors such as obesity, constipation and recurrent fecal impaction are associated with the presence of rectal diverticula probably because those conditions could increase rectal pressure. However, Martinez et al studied patients with rectal diverticula with anorectal manometry and found no changes in normal-pattern of the sphincter pressures, rectal sensitivity or complacence. Absence of supportive structures as coccyx, rectal infections or trauma, hemorrhoids, muscular atrophy or degenerative genetic anomalies are also considered risk factor for the occurrence of rectal diverticulum $8,14,15$.

Usually rectal diverticula need no surgical treatment since most cases are asymptomatic. Periodic follow-up is recommended due to possible metaplastic and posterior malignancy changes in the mucosa $a^{2,3,14}$.

Surgical intervention is reserved to symptomatic diverticulum or complications. The approach depends on the gravity or extension of the 
disease. Local drainage, diverticula invagination and diverticulectomy are preferred in single or located complications. Aggressive surgical procedures as retosigmoidectomy or abdominoperineal amputation are reserved for extent complicated disease or when malignancy is recognized ${ }^{3,8}$. In one of these patients a single diverticulectomy was performed because of the recurrent episodes of pain and located diverticulitis. He also presented bladder-compression symptoms. The surgery was effective and one year and six months after that the patient was totally asymptomatic.

\section{REFERENCES}

1. Damron JR, Lieber A, Truman S. Rectal diverticula. Radiology 1975;115:599-601.

2. Edwards VH, Chen MY, Ott DJ, King GT. Rectal diverticulum appearing as a prolapsed rectum. J Clin Gastroenterol 1994;18:254-5.

3. Giffin HZ. Diverticulitis of rectum: report of two cases operated upon, one of them with carcinomatous degeneration. Ann Surg 1911;53:533-7.
4. Halpert RD, Crnkovich FM, Schreiber MH. Rectal diverticulosis: a case report and review of the literature. Gastrointest Radiol 1989;14:274-6.

5. Henry MACA, Vercesi LAP, Lautenschlarger MFM. Divertículo de reto: apresentação de um caso. Arq Gastroenterol 1982; 19:139-41.

6. Jun S, Stollman N. Epidemiology of diverticular disease. Best Pract Res Clin Gastroenterol. 2002 Aug;16(4):529-42.

7. Kumar R, Shun A, Arbuckle S, Gaskin K. Diverticular rectal duplication with heterotopic gastric mucosa in a child: a rare cause of rectal bleeding. J Paediatr Child Health 2000;36:191-2.

8. Kyaw MM, Haines JO. Rectal diverticula. Radiology 1971;100:2834.

9. Martinez CAR; Priolli DG; Palma RT; Waisberg J. Divertículo do reto: relato de caso. Rev Bras Coloproct, 2003;23(4): 296-30.

10. Piercy KT, Timaran C, Akin H. Rectal diverticula. Dis Colon Rectun 2002; 45:1116-7.

11. Plavsic BM, Taider L, Drnovsek VH, Kogutt MS. Association of rectal diverticula and scleroderma. Acta Radiol 1995;36:96-9.

12. Spriggs EI, Marxer OA. Multiple diverticula of the colon. Lancet 1927;212:1067-74.

13. Tweddell TN. Diverticulitis of the rectum. An Surg 1964;70:569.

14. Walstad PM, Sahibzada AR. Diverticula of the rectum. Am J Surg 1968;116:937-9.

15. Weston SD, Schlachter IS. Diverticulum of the rectum. Dis Colon Rectum 1959;2:458-64. 